\section{La Dinámica de la} Modernidad en América Latina: Sociabilidades e institucionalización

The dynamics of Modernity in Latin America: sociabilities and institutionalization

\section{Carlos A. Gadea*}

\section{Resumen}

El presente trabajo pretende delinear algunos rasgos significativos de lo que se podría comprender como modernidad en América Latina. El interés radica en discutir cómo la caracterización de la particular experiencia histórica de la modernidad latinoamericana requiere de una interpretación del sentido y significado de los procesos de institucionalización de sociabilidades, disciplinamiento y uniformidad cultural. Un análisis de la modernidad en América Latina sugiere destacar aquellos dispositivos normativos que hacen referencia a la formalización e institucionalización de experiencias

Profesor de Historia; Doctor en Sociología Política por la Universidade Federal de Santa Catarina UFSC, Florianópolis, Brasil. Profesor del Programa de Pos-grado en Ciencias Sociales de la Universidade do Vale do Rio dos Sinos UNISINOS, Brasil. Av. Unisinos, 950, Bairro Cristo Rei, CEP 93.022-000, São Leopoldo, Rio Grande do Sul, Brasil, E-mail:cgadea@unisinos.br sociales. Así, pretende argumentarse que las múltiples prácticas modernizadoras parecen haber presentado una ambigua lógica institucionalizadora: por un lado, se caracterizan por sus marcados signos de fragilidad $y$ ausencia en determinadas esferas de la vida social, al mismo tiempo que denotan una fuerte presencia homogeneizadora y disciplinadora, materializadas en una institución, el Estado, que logró situarse por encima de las demás.

Palabras clave: modernidad, sociabilidades, institucionalización, América Latina.

\section{Abstract}

The present article intends to describe some significant traces of what could be understood as modernity in Latin America. Such an interest involves the discussion on how the characterization of a particular historic experience of Latin American modernity requires an interpretation of the sense and meaning of the process of institutionalization of sociabilities and cultural disciplination and uniformity. An analysis of modernity in Latin America suggests a focus on those normative mechanisms which refer to the formalization and institutionalization of social experiences. So, one intends to observe that multiple modernizing practices seem to have shown an ambiguous institutionalizing logic: on the one hand, they are characterized by clear signs of fragility along with absence in certain fields of social life, at the same time in which they denote a strong homogenizing and disciplining presence, materialized into an institution, the State, which happens to lie above all the others.

Keywords: modernity, sociabilities, Institutionalization, Latin America. 


\section{¿Qué modernidad?}

La posibilidad de preguntarse sobre la condición histórica de la modernidad en América Latina no ha dejado de inquietar a todos aquellos vinculados a las diferentes esferas de la cultura. Retornando hacia puntos imaginarios donde parece localizarse algunas respuestas, ejercemos una suerte de exotismo interpretativo al pretender incursionar en sus síntomas manifestados en la vida política, social y cultural. Así, han aparecido interpretaciones diversas, generalmente asociadas a los avatares políticos, los diferentes procesos de modernización económica y los cambios en las formas de observar el devenir cultural y sus formaciones consecuentes.

Lo que aquí se pretende es reintroducir el debate sobre la modernidad en América Latina, reconsiderando y reevaluando aquél iniciado a fines de los años 80 y comienzos de los 90 , visiblemente abandonado, por ejemplo, a partir del surgimiento del debate sobre la globalización y sus desdoblamientos económicos y socioculturales. Un neo-economicismo que especulaba acerca de las desventuras en torno de las llamadas políticas neoliberales, había provocado la salida de escena de varios pensadores y una virada en las iniciativas de investigación. Como consecuencia, las reflexiones y discusiones que se heredaron impidieron, lamentablemente, la intención por reconsiderar (desde una multiplicidad de perspectivas disciplinarias) nuestras construcciones históricas sobre la modernidad y el análisis de la eventual crisis de sus connotaciones normativas, políticas y sociales.
La idea de fondo es enfatizar que un análisis de la modernidad en América Latina sugiere destacar aquellos dispositivos normativos que hacen referencia a la formalización e institucionalización de experiencias sociales y culturales. La modernidad aparecería, así, como una categoría claramente definible debido al producto de una construcción sociológica basada en la clásica dicotomía entre ella y la "tradición". Mientras algunos autores sugieren que "habría que partir, por ejemplo, por entender el contexto operativo de la cultura que suele llamarse tradicional (y en algunos países, oligárquica), si se desea luego abordar el análisis de las rupturas y continuidades que implica la emergencia de la modernidad latinoamericana" (Brünner 1992: 43); el análisis aquí asumido sugiere relativizar todo esfuerzo por comprender "lo moderno" como síntesis histórica sustitutiva de "lo tradicional". Esta dicotomía puede operar como "tipo ideal" para diferenciar interrelaciones sociales y sus contextos de producción y escenificación, pero no para sugerir etapas de una evolución histórica. No se trata de etapas o estadios históricos "objetivos", del pasaje de "mundos materiales y simbólicos" de menor grado de complejidad hacia otros de mayor complejidad (tradición-modernidad y, eventualmente, posmodernidad), o del advenimiento o emergencia de una condición social y cultural que acabaría sustituyendo a una anterior.

En América Latina, "lo moderno" se rodea de una nebulosa cultural y social ni siquiera fácilmente constatable cuando se la enfrenta a su otro: la tradición. En tal sentido, es posible deducir que esta falsa dicotomía conduce a una identificación poco evidente de "lo moderno", a una especie de hibridación de las experiencias y prácticas sociales definidora de una ausencia 
de aquello propiamente moderno o tradicional. Tradición y modernidad, como bien constata Richard (1999: 373), dejan de contraponerse bajo el signo rupturista del antagonismo entre lo viejo y lo nuevo: la modernidad no llega para sustituir a la tradición, sino a entremezclarse con ella. De todas formas, ni siquiera es una especie de apología al hibridismo lo que daría respuesta a posturas de ésta índole, sino la comprensión de la complejidad analítica de ofrecer transparencia a un mundo sociocultural por demás dinámico.

No existe una línea de evolución inmutable de la modernidad, un devenir histórico a priori delimitado por determinadas fuerzas ideológicas, políticas e institucionales. Por esto, el desarrollo de la modernidad en América Latina en absoluto supone una repetición destemporalizada de una supuesta modernidad gestada en Europa o en los Estados Unidos. Si se habla, por ejemplo, de grados de institucionalización y formalización de la vida social (en una constante expansión espacial y temporal como características de la modernidad) deben considerarse que han sido, y siguen siendo, procesos que concilian cadenas de interacción social particulares de acuerdo a los grados diversos de contingencia presentados. ¿Puede suponerse, entonces, que es posible comprender la existencia de una "particular" modernidad en América Latina? Obviamente que no. Ni particularidad, que significaría una representación errónea de un proceso histórico general, en el cual la Europa moderna y América Latina se constituyen en evidente interrelación, y mucho menos la repetición o transferencia lineal de "una realidad" y sus instituciones hacia "una realización" y sus adaptaciones de ordenamiento normativo en un contexto ajeno.
Lo que interesa ver al analizar y reflexionar sobre la modernidad en América Latina son aquellos dispositivos normativos que imponen (o pretenden imponer) un determinado orden sociocultural. De esta forma, "lo moderno" puede adquirir su locus constitutivo y su más concreta materialización en un proceso de universalización de normas, generalización de valores y formalización de las interacciones sociales: en la medida que se produce una mayor integración en la lógica institucional, más se estandarizan las prácticas sociales y se introducen nuevas limitaciones respecto de las actividades, acciones e identidades permitidas y eventualmente válidas y legítimas.

Los procesos históricos independentistas y sus anhelos por un orden liberal, las posteriores narrativas nacionalistas y románticas de fines de siglo XIX e inicios del XX, las costumbres $y$ rituales cotidianos enmarcados en el disciplinamiento y la racionalización, el control de la sexualidad, la escuela, el médico, los presidios; todo esto puede entenderse dentro de iniciativas políticas, culturales y económicas cuyo gran relato legitimador descansa en los fundamentos epistemológicos del proyecto histórico clásico de la modernidad. En América Latina, éste se iniciay consolida, paulatinamente, con la industrialización masiva, la urbanización en gran escala y los diferentes dispositivos de racionalización de la vida cotidiana. La "domesticación de los instintos", la sujeción de las voluntades individuales, la canalización de deseos personales hacia fines generales y el disciplinamiento de ambiciones y albedríos singulares en función de objetivos sociales que se materializaron con los estatutos jurídicoinstitucionales y la regulación y control social, son algunos ejemplos de ello (Mansilla 1992). Todo remite a la analogía, hecha por Weber, 
acerca de la "militarización de la sociedad" a fines del siglo XIX y comienzos del XX, en la que la "jaula de hierro" establecía un principio de inclusión social en que cada individuo tenía su lugar, y cada lugar una función definida, estática y fija (Sennett 2006). Se llega, de esta manera, a suponer que referirse a "lo moderno" en el heterogéneo contexto latinoamericano sugiere destacar aquellos procesos que hacen referencia al disciplinamiento (Foucault 1988; 1989 ; 1992), formalización, uniformización e institucionalización ${ }^{1}$ de experiencias sociales, culturales y políticas.

\section{Modernidad y sociabilidad}

Como lo analizó el historiador José Pedro Barrán (1990), la "nueva sensibilidad civilizada" supuso un sistema de control social, de vigilancia y de construcción de civilidad en el cual las instituciones como el maestro, el médico, el sacerdote y el Estado cumplieron papeles fundamentales. Difícil resulta disociar estos sujetos sociales, figuras culturales 0

Se hace referencia a la "teoría de la institucionalización" de Berger \& Luckmann (2001 [1966]). Los autores argumentan que: "La institucionalización ocurre siempre que se manifiesta una tipificación recíproca de las acciones habituales por tipos de actores (...). Las instituciones, también, por el simple hecho de existir, controlan la conducta humana estableciendo padrones previamente establecidos de conducta, que la canalizan en una dirección por oposición a muchas otras direcciones que serían teóricamente posibles. Es importante acentuar que este carácter controlador es inherente a la institucionalización en cuanto tal, anterior a cualquiera de los mecanismos de sanciones específicamente establecidos para apoyar una institución o independientes de esos mecanismos. Tales mecanismos (cuya suma constituye lo que generalmente se llama sistema de control social) existen evidentemente en muchas instituciones y en todas las aglomeraciones de instituciones que llamamos de sociedad. (...) Decir que un segmento de la actividad humana fue institucionalizado ya es decir que este segmento de actividad humana fue sometido al control social (79-80) (traducción del portugués por parte del autor). instituciones unas de otras, en la medida que actuaron, desde comienzos de siglo XX en América Latina, como los portadores de los preceptos modernizadores y modernistas en la cultura, las costumbres y los gustos. Así, es posible establecer la trilogía conceptual que caracterizaría esta modernidad: modernización, que se originaría a través de estas instituciones, y que aspirarían a una universalización de los preceptos políticos, morales y socio-culturales.

Ningún supuesto "orden" pre-moderno podría "integrar"y vinculara aquellos hombres y mujeres de fines de siglo XIX y comienzos del siglo $X X$. Luego de las variadas luchas regionales, políticas, religiosas y de "modelos de identidad" sobre las ideas relativas a la construcción de una nación, el peso sobre la consolidación de un determinado "orden" de la sociedad recaería en instituciones especializadas funcionalmente (instituciones políticas, educativas, de higiene y salubridad, económicas y jurídicas) ${ }^{2}$. A partir de esto, fue una ambigua lógica institucionalizadora lo que se expresó en América Latina. Ambigua porque se caracteriza por sus marcados signos de debilitamiento y ausencia en determinadas esferas de la vida social ${ }^{3} \mathrm{y}$, al mismo tiempo, por su fuerte presencia uniformizadora, materializada en una institución por encima de las demás. Una institución estableció órdenes jerárquicos en prácticamente todas ellas, para luego absorberlas y asimilarlas como

\footnotetext{
"Max Weber distinguió entre esferas sociales y esferas de valores (porque cada esfera tiene su propia deidad); pero nosotros preferimos el término "instituciones" con objeto de reforzar la idea de que existen varias en la misma esfera, al igual que también existen instituciones a horcajadas de varias esferas, y multifuncionales, y cada una de ellas puede adoptar una independencia relativa respecto a las demás" (Heller \& Fehér, 1994: 146).

3 Percepción recurrente históricamente para referirse a los frágiles canales institucionales que promuevan la libertad y la justicia social, la democracia y la igualdad.
} 
propias de su dinámica de acción e influencia ideológica. Es justamente este proceso el que determinaría su capacidad para adquirir sus rasgos de diversidad y pluralidad de funciones. Las funciones políticas, jurídicomorales, entre otras, adquieren un puesto de jerarquía institucional concentradas en la figura del Estado. Es de esta manera como el orden social moderno se hacía diferente de la piramidal dinámica pre-moderna; en parte, claro. En América Latina, este desenlace ordenador y organizador de la vida socio-cultural logra definir a su modernidad como un producto histórico que no olvida que ha sido precedida por un "otro orden" identificado con la injusticia, el subdesarrollo, la pobreza, la violencia y la heterogeneidad, con un "orden caótico". La "naturaleza", sinónimo de desorden, era finalmente vencida. Era la diferencia ordenada jerárquicamente del pluri-verso pre-moderno en América Latina la que fue finalmente vencida. En conclusión, un específico "mapa" jerárquico desaparecería $\mathrm{y}$, eventualmente, sería sustituido. Dentro del orden moderno ${ }^{4}$, la jerarquía social se establecería en el nivel de las instituciones especializadas, destino que no carecería de fuertes críticas y crisis, conflictos y violencia.

Las prácticas sociales o sociabilidades formaban un aparente orden articulado, o al menos era lo que se pretendía. La supuesta modernidad latinoamericana partía de la idea de que la pluralidad y diversidad de las sociabilidades dificultaba la tarea de imaginarse un actor supuestamente colectivo

"Por 'orden social fundamental' queremos indicar la estructura constante de, y el mecanismo para, la distribución (ordenación) y redistribución (reordenación) de la libertad y de las oportunidades en la vida junto con el mantenimiento (reproducción) de la unidad social completa" (Heller \& Fehér, 1994: 140-141). capaz de intervenir en nombre y a favor de ideas universalistas. Dotado de una alta razón histórica y de una voluntad unitaria, uniformizadora y homogeneizadora, el Estado será ese actor portador de cohesión y coherencia de las prácticas perfectamente organizadas y crecientemente institucionalizadas. Así, Estado y Derecho materializarían el poder disciplinador, teniendo en cuenta que el Derecho es, antes que nada, un "principio de racionalidad". Más allá de que encarne un conjunto de reglas pretendidamente universales y abstractas que circunscriben el poder y el Estado, el Derecho no existe en cuanto tal. Lo que existe son prácticas jurídicas que se refieren a un específico "principio de racionalidad", y este principio es el que ordena las prácticas legislativas, las doctrinas, la jurisprudencia, la aplicación y distribución de justicia (Ewald 1993).

\section{Sociabilidades e institucionalización}

Las instituciones de un mundo moderno implican la historicidad y el control. Las instituciones tienen siempre una historia, de la cual son producto. De aquí que resulte imposible comprender las lógicas institucionales en América Latina sin advertir el complejo proceso histórico en que han sido producidas. Puede advertirse, consiguientemente, que las diferentes historias consagradas han siempre puesto a la dinámica de la modernidad bajo el fuego cruzado del disciplinamiento, por un lado, y la liberación de las ataduras pre-hispánicas, coloniales y comunitarias, por el otro (ver Wagner 1997). Si bien son reconocidas las historias de liberación que acompañaron la dinámica moderna en América Latina, la lógica disciplinaria y uniformizadora se ha establecido, 
también, en factor constitutivo de ella. Las instituciones, por el simple hecho de regir la vida colectiva (y hasta por el hecho de ellas existir), controlan la conducta estableciendo padrones previamente definidos, canalizándola en una dirección específica en desmedro de muchas otras direcciones que serían teóricamente posibles. Este carácter controlador (y disciplinador) es inherente a la institucionalización en cuanto tal. De esta manera, afirmar que una concreta actividad individual o colectiva (política, sexual, etc.) fue institucionalizada, es afirmar que ha sido finalmente sometida al control social (Berger \& Luckmann 2001).

Con el tiempo, la objetividad del mundo institucional se expresa como una realidad dada, como un mundo que se torna el mundo. Al tornarse "real" de manera más sólida, ya no parece poder ser transformado con tanta facilidad. La flexibilidad no es una característica que se haga visible para todos. Al contrario, el mundo institucional transmitido en los procesos de socialización no es completamente transparente, ya que al no participar en su formación, a muchos se les presenta como una realidad objetiva, dada, evidente e inalterable. Para amplias capas de población latinoamericana, desde el medio rural inhóspito y lejano, hasta el anonimato suburbano de las grandes ciudades, las instituciones se perciben como "realidad exterior", aunque gradualmente interiorizadas en sus cotidianos. Tienen un poder coercitivo, dado el poder de los mecanismos de controly disciplinamientoligados a ellas. Sin embargo, el mundo institucional exige legitimación, es decir, modos por los cuales puede ser explicada y justificada su funcionalidad. Esto se debe a que la realidad del mundo social que encarna es histórica, haciendo que las nuevas generaciones tomen contacto con él como tradición y no como memoria de vida. Aquí es donde radica, primeramente, un problema de legitimación que hace de la variable temporal un factor crítico. ¿Por qué? Porque el conocimiento que se adquiere de la historia institucional específica es recibido por una "transmisión oral" de las generaciones más viejas. Se torna imprescindible, entonces, interpretar para las generaciones de más jóvenes el significado original de las instituciones en varias fórmulas legitimadoras. Estas tendrán que ser lo suficientemente convincentes en lo que se refiere al orden institucional para que las generaciones de jóvenes sean convencidas. Pero va a ser, justamente, un alejamiento gradual de los elementos fundadores del mundo institucional lo que estaría generando la crisis propia de la dinámica de la modernidad. Y, al mismo tiempo, sería la aparente dificultad de los diferentes lenguajes legitimadores de ser "aprehendidos" por las nuevas generaciones durante el mismo proceso que las socializa en el orden institucional la que sugiere referirse a sociabilidades que estarían "escapando" a la dinámica de la modernidad.

Pero en América latina, en cuya mezcla sociocultural se basa gran parte de sus dinámicas modernizadoras, el desarrollo de mecanismos concretos de disciplinamiento y control social ha conseguido tornarse necesario con la "objetivación de las instituciones". Seharecurrido siempre a ellas para lograr superar eventuales crisis que, en muchas ocasiones, eran propias de su inadecuada funcionalidad, "artificialidad" y desacomodo en un determinado contexto socio-cultural. Rápidamente, si las instituciones pasaban a ser realidades divorciadas de su fundamento original en los procesos sociales de los cuales surgían, se establecían una serie 
de sanciones correspondientes para quienes las transgredían de alguna forma, ya que las instituciones pretenden tener autoridad sobre los individuos independientemente de los significados particulares que estos puedan atribuir a cualquier situación concreta. La prioridad de las definiciones institucionales de las situaciones era coherentemente preservada de las críticas, transgresiones y tentaciones individuales de redefinición.

El problema acerca de la capacidad de redefinición del mundo institucional radica en el campo de su legitimación. Se debe estar de acuerdo que el compendio de legitimaciones es construido sobre el lenguaje, usándose, en teoría, como su principal instrumento. Así, la dinámica atribuida al orden institucional forma parte del acervo histórico y socialmente disponible de conocimiento. Esto se relaciona con la idea de que la transmisión del sentido y significado de una institución se basa en el reconocimiento social de ésta como solución potencialmente permanente de un problema también permanente de un orden social específico. Los potenciales actores sociales de acciones institucionalizadas deben tomar conocimiento de esos significados, suponiendo, consiguientemente, alguna forma de proceso educativo, al que en muchas ocasiones se ha entendido como sinónimo de una ampliación de la ciudadanía. Si bien son cuestiones bastante diferentes, y que se refieren a esferas semánticas distintas, pueden ser correspondientes a una tentativa por conseguir legitimaciones apropiadas para un determinado mundo institucional eventualmente herido de legitimación. Se encontrará en la "multiplicidad" de lenguajes legitimadores del mundo institucional, de la fragmentación social (como algunos gustan decir) consecuente, el problema más serio para una dinámica de la modernidad que encarna la necesidad de integración institucional para las diversas sociabilidades a partir de un universo de significaciones socialmente compartido.

\section{Institucionalización y normatividad}

La dinámica de la modernidad en América Latina no reconoció límites culturales y políticos para su continua reafirmación Puede mencionarse el Facundo de Sarmiento como uno de los discursos de la modernidad latinoamericana que enfatiza esta característica (ver Castillo Durante 2000: 163-189). Cuando algo se interponía, o lo combatía directamente a través de la violencia (como con las culturas indígenas, aunque no siempre triunfante), o lo intentaba absorber bajo sus postulados de futuro ordenamiento social. Las múltiples prácticas modernizadoras no reconocían a priori límites que lograran frenar su embalo. Habiéndolos, se los trascendía. Cuestionándolo todo, no destruían, sino que mantenían el supuesto "orden moderno".

Pero en América Latina no es posible referirse a un específico "orden moderno". Resulta más apropiado referirse a una dinámica de la modernidad, a una serie de reglas que se van presentando en contextos y temporalidades diversas en pro de un "eventual orden" que estaría por presentarse luego de la prolongada lucha contra los vestigios de lazos pre-modernos que atentan contra el desarrollo social y el progreso moral. Sin un específico "orden", ni siquiera funcionando en el imaginario cultural, la sociabilidad latinoamericana se presenta siempre ante un espejo que devuelve imágenes contradictorias, inciertas y cambiantes. La idea de dinámica sugiere esta inacabada sensación 
de estar en un orden social que, existiendo, se pretende alcanzar. Dinámica y orden entran en un juego dialéctico.

Es en América Latina donde más se puede afirmar que el término "proyecto de la modernidad" no es del todo apropiado. Un proyecto puede llevarse adelante de diversas formas, existiendo, asimismo, un punto en que es posible decirse que se ha logrado. En este sentido, la modernidad no es un proyecto. Sus categorías están en un estado de actividad constante: "Habermas menciona el proyecto inacabado de la modernidad. Ésta es una buena expresión si añadimos que el proyecto nunca se acabará, porque acabarlo significa matarlo. La modernidad (...) puede asumir variaciones prácticamente infinitas al igual que la pre-modernidad, pero su dinamis las incluyen a todas in nuce" (Heller \& Fehér 1994: 139).

Así parece manifestarse en las prácticas sociales históricamente presentadas en la heterogénea América Latina. Las "variaciones prácticamente infinitas" que puede asumir la dinámica de la modernidad pueden distinguirse en diferentes experiencias culturales sedimentadas que han cubierto al escenario latinoamericano con un manto de diversas prácticas políticas y sociales en absoluta convivencia, puja y lucha: por ejemplo, lo que corresponde al universo de la religión, de las culturas indígenas, de las diversas manifestaciones afro-americanas, del "mundo bárbaro" asociado al indomable espacio rural, de las estructuras políticas clientelistas herederas de prácticas "no modernizadas", entre otras.

Más allá de que la lógica institucional latinoamericana pretendía abolir las diferenciaciones culturalmente surgidas en el mismo proceso de la dinámica de la modernidad, el despliegue de la "formalización" de las sociabilidades iba a tener que lidiar con una multiplicidad de maneras de llevar adelante la propia institucionalización. La diversidad cultural o la "multiplicidad de lenguajes" que históricamente iban a ser transformadas o simplemente cuestionadas por el desarrollo de la modernidad, en todo momento generaron mecanismos de tensión lo suficientemente fuertes como para transgredir, criticar y cuestionar, reiteradamente, la lógica institucional implantada por una elite intelectualmente preparada y políticamente educada para tales finalidades. Una amplia gama de movimientos y actores sociales así lo han evidenciado, como últimamente lo ha registrado el despliegue movilizatorio y discursivo del movimiento indígena neozapatista de México.

Quizás es una lógica de la contaminación, del conflicto continuo, y de una aspiración modernizadora que aisladamente se propone una tarea mientras consigue realizar otra, lo que puede definir la dinámica de la modernidad en América Latina. Culturalmente no hay dudas de eso. La referencia al hibridismo no es una novedad a esta altura. La cuestión más curiosa es la comprensión de una específica "formalización" de las acciones cotidianas, de las sociabilidades, como especie de re-interpretación del mundo y de re-clasificación de sus elementos con una mirada puesta en el aumento de la capacidad de control y dirección, de "destino" social y político. Es en esta "formalización" que se apoya la conquista de las instituciones modernas en lo referente a la aplicación de su campo de acción (Wagner 1997: 68). 
En América Latina, no en menor escala que en los contextos europeos y norteamericanos, el despliegue de "formalizaciones" de las sociabilidades representó un determinado esquema clasificatorio, ordenador, reductor y de exclusión de maneras de "estar en el mundo". Esto es consecuencia, obviamente, de la construcción de conceptos o categorías que representan una realidad previamente interpretada del mundo social, por la que se fijan normas de conducta inclusivas y excluyentes, así como se estructuran posibilidades de acción y el trazado de fronteras de lo legítimo y lo excluido. Fronteras en el sentido de "convenciones sociales" creadas en condiciones particulares. También en el sentido de "crear identidades" sociales que, con el tiempo, se presentarán para todos como "naturales". Va a resultar un gesto crítico la incredulidad en esta posibilidad de poder "crearse" un código ético no ambivalente y sin contradicciones (Bauman 1997: 15), es decir, un código clasificatorio de lo correcto y lo no correcto, de jerarquías de valor arbitrariamente puestas en la escena social.

No obstante, al referirse a la institucionalización en América Latina, varios análisis reiteran su posibilidad en la medida que ella sea regida y se materialice en la esfera política, en la órbita de la legalidad y el derecho, en definitiva, en los marcos jurídicoregulatorios de la vida en sociedad. Piénsese, por ejemplo, en el diagnóstico ampliamente difundido de la "baja institucionalización" en el contexto latinoamericano debido a la debilidad del derecho y el constitucionalismo como instituciones (Peruzzotti 2001): “¿Cuáles son las causas de la baja institucionalización en América Latina?(...) el bajo nivel en la construcción institucional exhibida por las sociedades latinoamericanas está íntimamente ligado a las formas asumidas en el proceso histórico de autoconstitución de sus sociedades civiles, más específicamente, con la erosión de los acuerdos legales constitucionales por parte de formas populistas de autoentendimiento" (162).

Puede decirse que, en parte, es cierto todo esto. En parte porque la supuesta "precariedad institucional" diagnosticada no es tal si la entendemos como incapacidad de regular ciertos mecanismos de convivencia sociocultural. Los valores y normas, generados en la misma dinámica de socialización, son adquiridos, y forman parte, del medio social en que se hacen presentes. De igual manera, su institucionalización es también parte de ese ambiente social, no sin resistencias y contradicciones. El proceso de institucionalización en América Latina corresponde a una particular (o a particulares) dinámica socio-cultural y a los acuerdos contingentes diseñados durante el mismo proceso de internalización de códigos colectivos y valores. La lógica institucional, atendiendo inclusive a las variadas formas de su desarrollo, se materializó incorporando o, mejor dicho, con la co-participación de aquellos elementos histórico-culturales, políticos y de valoraciones definibles como "exteriores" a la dinámica de la modernidad. Todas las figuras definidas como "exteriores" a ella, como podría ser lo indígena, lo negro, el caciquismo, el clientelismo, el "compadrazgo", figuras supuestamente "pre-modernas", han sido, y continúan siendo, protagonistas también centrales de la particularidad de la lógica institucional latinoamericana $y$, por consecuencia, de la propia dinámica de la modernidad (ejemplificada claramente en la ampliamente difundida figura 
socio-jurídica de la corrupción, especie de reverso del juego institucionalizador). Esta característica, más allá de contradecir el diagnóstico de la "precariedad institucional", conduce a una institucionalización aún más amplia, más inalterable y crecientemente más compleja y dinámica. No es que no exista institucionalización y "formalización" de las sociabilidades, según los criterios definidos y definibles por la dinámica de la modernidad, y una supuesta cohesión social, por la presencia de prácticas políticas y culturales como el "populismo" o el autoritarismo. La lógica institucional en América Latina se caracteriza por ser producto de las diferentes experiencias culturales sedimentadas y la variedad de mecanismos y recursos sociales que le son propias. Por eso, cualquier respuesta a la lógica institucional representa lidiar con una multiplicidad de locus culturales y éticos.

Las presiones normativas, en el sentido de institucionalización de sociabilidades tolerables y moralmente aceptadas, parecen rendirse a una dinámica de la modernidad que, al mismo tiempo, ha generado la deslegitimación de sus propios fundamentos. Una supuesta crisis adviene como consecuencia de presiones tendientes a favorecer y transformar la propia configuración de las instituciones. Si los problemas se localizan en el campo de la legitimación, no cabe duda que la lógica institucional latinoamericana presenta signos de crisis.

En aquellos eventuales "modelos modernizadores" paradigmáticos, como puede ser el caso de países como Uruguay, en los que la progresiva y exitosa secularización política y social del país (por ejemplo, con la temprana separación de la Iglesia del Estado) supuso una "alta institucionalización", los factores de crisis se han hecho tan presentes como en aquellos de supuesta "baja institucionalización". Si por modernización y desarrollo se comprende industrialización, el caso uruguayo denota un modelo en el cual, a comienzos del siglo XX, "la industria promovería la transformación de las arcaicas estructuras rurales, el mejoramiento de la distribución del ingreso, la modernización de la sociedad y el desarrollo de un sistema político armónico, en que el acuerdo social se derivaría de la articulación de productores y consumidores, de empresarios y asalariados, de un mercado nacional en expansión" (Rama 1987: 65).

El "mito" democratizador e igualitarista, generador de una amplia "clase media" en el Uruguay, vino a tomar fuerza y adquirir fundamento en ese proceso de industrialización y consiguiente modernización de la sociedad ${ }^{5}$, "mito" que, por ejemplo, sirvió en su momento para tomar distancia del "modelo argentino", al cual muchas veces se sentía dependiente. El problema histórico de la definición de una identidad uruguaya cualitativamente diferente de la argentina (al que tantos trazos sociales asemejan) pareció resolverse con una autoimagen en la que el "modelo modernizador" en curso se fundamentaba sobre la base de una muy fuerte integración en los valores democráticos, de exaltación de las instituciones y de un proceso de integración social sin autoritarismo y populismos (61). La paciente consolidación de una sociedad

El proceso de industrialización registró un "decenio glorioso" entre 1945 y 1955, con una tasa anual de crecimiento del 8,5\%. Esto conllevó un intenso desarrollo de la educación y la seguridad social, de alta movilidad social ascendente. El país vivía bajo una auto-admiración desmedida, que los dirigentes políticos transmitían como un credo de la certidumbre. 
presumiblemente moderna no podía sentirse mejor en la primera mitad del siglo XX. Un Estado fuerte "formó" la sociedad de acuerdo con las prioridades de integración nacional, de institucionalización y de identificación entre sociedad y Estado a través del proceso político democrático. Ello significó una negación por asumir los inevitables conflictos con los sectores sociales más "retardatarios" y, en el otro extremo, más "críticos", ya que al hacerlo tendría que haber postergado la dinámica de integración democrática y continuar una dirección del proceso a partir de un Estado relativamente autónomo, con el riesgo inminente del autoritarismo político. Un amplio sector social, muy poco ligado a las transformaciones del mundo urbano, y más heredero de prácticas cotidianas de raíces autoritarias y de dependencias personalizadas a favor de cúpulas sociales regionales o productivas, iba a ser uno de los factores que, a mediano plazo, incidiría en la reformulación y crisis del "modelo modernizador". Así, la integración democrática estableció en el largo plazo la identidad de la sociedad uruguaya, pero su precio en el corto plazo fue una especie de "consenso integrador" que implicaba el freno al cambio (42), así también como la dificultad de pensarse alternativas al modelo.

Esta situación se tornaba evidente cuando aquellos sectores sociales y económicos que habían recibido ciertos privilegios y gratificaciones durante el auge modernizador se habían acostumbrado a una imagen de protección del Estado, no teniendo motivos demasiado evidentes para querer cambiarla. Lo que en conclusión se había producido era una "sacralización de las instituciones" $y$ de los valores sociales que en ellas se sustentaban. Así, los diferentes actores sociales transformaron una oposición que giraba en torno a los fines políticos y económicos (en su conjunto, a la "vida en sociedad") en una oposición basada en los medios performáticos de funcionamiento del sistema político. Bajo la operacionalidad de las instituciones, la vida socio-cultural uruguaya debería y tendría que dar solución a sus desajustes coyunturales. Sin duda, radicó en un acentuado conservadorismo y un excesivo ideal de seguridad y certidumbre, de confianza en las instituciones, el eventual fracaso de la aventura modernizadora. A un Estado sin proyecto le correspondía una sociedad que concebía el desarrollo como un dato externo a la sociedad. Es decir, "el ciclo iniciado con el proyecto innovador (modernizador) en que una elite política creó la sociedad desde el Estado, finalizaba con una sociedad que pasaba a controlar el Estado con un conjunto de reivindicaciones particularistas, más propias de la ilusión de la política que de la política misma; controlaba el Estado, en lugar de una elite, una burocracia política que insistía en negociar cuando ya no tenía medios materiales ni simbólicos con que hacerlo" (82). Asimismo, "la alta capacidad de sobrevivir, en un largo ciclo de decadencia, de las instituciones y de los valores políticos, de las formas de expresarse culturalmente, y también la continuidad de los estancados y obsoletos mecanismos de producción, ponen de manifiesto la fuerza de la integración nacional. Esta integración llega al límite de maneras de ser, pensar y hacer tan coherentes, que no dejan paso a las tensiones productoras de cambios; en consecuencia, puede hablarse de una sociedad hiperintegrada" (158).

Si la "baja institucionalización" en los países 
latinoamericanos supuso la "debilidad del derecho", ¿qué sugiere el "modelo modernizador" con "alta institucionalización" política y social? La sociedad uruguaya, y en especial sus clases medias (su mesocracia), sus políticos e intelectuales, sufrieron (y sufren) de una fuerte "crisis de identificación", ante la cual surgieron una serie de respuestas: la guerrilla urbana de los años 60 y 70, los movimientos de izquierda política, la "utopía institucionalizadora" y "restauradora" (no sin variantes) del modelo en manos de algunos militares (el autoritarismo), los renovados movimientos estudiantiles y sindicales, la deserción cultural, la indiferencia política y la emigración.

Indudablemente que el caso de Uruguay puede visualizarse en otras configuraciones políticoinstitucionales de la región. Cada vez que se constaten problemas ante la incapacidad y los intereses prácticos de un sistema políticoinstitucional que no encuentra nada mejor que tratar de acomodar "nuevas situaciones sociales" en la antigua normatividad e institucionalidad política, estamos frente a un caso de una dinámica histórica de la modernidad similar. El desafío parece siempre intentar generar una nueva normatividad para las emergentes nuevas situaciones reales de poder, que en el contexto latinoamericano hacen referencia a la descomposición paulatina de la cultura política e institucional de varias décadas atrás.

\section{Breves consideraciones}

La dinámica de la modernidad asume, en América Latina, una especie de principio de reversibilidad. Ni la "alta" o la "baja" institucionalización pueden ser consideradas premisas constitutivas de ella. Aquellas "especulaciones" que se refieren al grado diverso de institucionalización de las esferas sociales, políticas y morales como un progresivo movimiento de "conquista" en torno de libertades y garantías de "convivencia" no pueden adquirir una validez empírica generalizable. La suposición analítica en la dirección de "baja institucionalización" como sinónimo de potencial autoritarismo, desequilibrios políticomorales o relaciones sociales sobre la base de diferencias que lesionan identidades, subvierte las experiencias que a posteriori revelan el alto grado de contingencia y ambigüedad de las sociabilidades. En América Latina, la lógica institucional ha revelado, y aún revela, una reversibilidad creciente en lo que respecta a reglas y códigos de convivencia social y mecanismos de negociación espontánea de eventuales problemáticas. No han sido los procesos de "formalización" de sociabilidades, encarnados en instituciones reguladoras y ordenadoras, los que han contribuido a una mínima garantía de convivencialidad.

Tal vez la metáfora de las oscilaciones del "péndulo de la modernidad", tal cual Heller \& Fehér (1994) mencionan, puede ser análoga a esta interpretación. La fantasía de una marcha constante "hacia delante", conquistando aquellos espacios "no legislados", en estado de "ausencia de control", implica algún mecanismo de las sociabilidades cuyo origen se torna completamente misterioso. El principio de reversibilidad niega la validez de una "mecánica social", de una dinámica lineal de los acontecimientos. Siendo así, "(...) en cuanto la modernidad ha alcanzado su forma adecuada al menos en el arte de gobernar, las energías humanas no albergan necesariamente la 
intención de presionar constantemente "hacia adelante" ni de negociar una trascendencia absoluta" (156).

No se trata de otra cosa que de cuestionar una forma de interpretar la realidad social latinoamericana basada en los a prioris de la posibilidad de comprender y "legislar", de ofrecer coherencia a las prácticas sociales y racionalidad a las acciones. Esto es así porque toda sociología que otorga centralidad a la institucionalización, en América Latina, sólo comprende y considera objetos de su estudio sociabilidades que se encuadrarían en esquemas de acción institucionalizados, "bajo control", definibles como "racionales" y, por consecuencia, cuantificables, medibles y predecibles. De esta manera, no se puede escapar a otro principio constitutivo de las instituciones de la modernidad: el principio de fragilidad, ya que cada vez menos tienen en donde fundamentar sus prácticas y discursos, nada que no sea provisorio, parcial y contingente, nada desde lo que pueda tratar de legitimar (y convencer) a partir del metarrelato del progreso, la historia y el desarrollo.

\section{Bibliografía}

Barrán, José Pedro. 1990. Historia de la sensibilidad en el Uruguay. Tomo I y II. Montevideo: Banda Oriental.

Bauman, Zigmunt. 1997. Ética pós-moderna. São Paulo: Ed. Paulus.

Bayce, Rafael. 1989. Cultura política uruguaya: desde Batlle hasta. Montevideo: Fondo de Cultura Universitaria.

Berger, Peter \& Luckmann, Thomas. 2001 [1966]. A construção social da realidade. Petrópolis: Vozes.

Borges, Jorge Luis. 1998. Ficciones. Buenos Aires: Alianza.

Brünner, José Joaquín. 1992. América Latina: cultura y modernidad. México: Grijalbo.

México: FCE.

$$
\text { 1998. Globalización cultural y Posmodernidad. }
$$

Castillo Durante, Daniel. 2000. Los vertederos de la Postmodernidad: literatura, cultura y sociedad en América Latina. Ottawa: Dovehouse.

Chambers, lain. 1994. Migración, cultura, identidad. Buenos Aires: Amorrortu.

Deleuze, Gilles. 1991. "Posdata sobre las sociedades de control". Christian Ferrer (comp.). El lenguaje literario. Montevideo: Ed. Nordan.

Ewald, F. 1993. Foucault, a norma e o direito. Lisboa: Veja.

Foucault, Michel. 1988. "El sujeto y el poder". Revista Mexicana de Sociología.

1992. Microfísica del poder. Madrid: La Piqueta.

Gadea, Carlos A. 2004. Acciones colectivas y modernidad global. El movimiento neozapatista. Toluca-México: UAEM. 2004b. "América Latina. Movimientos sociales e izquierda política”. Relaciones 246.

García Canclini, Néstor. 1995. Culturas Híbridas. Buenos Aires: Sudamericana.
Heller, Ágnes \& Ferenc, Fehér. 1989. Políticas de la postmodernidad. Barcelona: Península.

Hopenhayn, Martín. 1988, "El debate post-moderno y la dimensión cultural del desarrollo". Quijano, Vega, casullo, García Canclini y otros. Imágenes desconocidas. La modernidad en la encrucijada postmoderna. Buenos Aires: Clacso.

Larraín, Jorge. 1997. "La trayectoria latinoamericana a la modernidad". Estudios Políticos 66.

Mansilla, H. C. F. 1992. Los tortuosos caminos de la modernidad. América Latina entre la tradición y el postmodernismo. La Paz: Centro Boliviano de Estudios Multidisciplinarios.

Perelli, Carina \& Rial, Juan. 1986. De mitos y memorias políticas: la represión, el miedo y después... Montevideo: Banda Oriental.

Peruzzotti, Enrique. 2001. "Modernización y juridización en América Latina. Hacia una crítica del proceso de desarrollo latinoamericano". Metapolítica 5, 18.

Rama, Germán. 1987. La democracia en Uruguay. Una perspectiva de interpretación. Buenos Aires: Grupo Editor Latinoamericano.

Richard, Nelly. 1999. "Latinoamérica y la Posmodernidad". Revista La Torre 12.

Rincón, Carlos. 1995. La no simultaneidad de lo simultáneo. Postmodernidad, Globalización y Culturas en América Latina. Bogotá: Universidad Nacional.

Sennett, Richard. 2006. A cultura do novo capitalismo. Rio de Janeiro: Record.

Toro, Alfonso de \& Toro, Fernando de. 1999. El debate de la postcolonialidad en Latinoamérica. Alemania: Vervuert.

Wagner, Peter. 1997. Sociología de la modernidad. Barcelona: Herder. 
